\title{
Erratum to: HIV Housing Helps End Homelessness and HIV/AIDS in the United States
}

\author{
Julie Hilvers, Christine C. George and Arturo V. Bendixen
}

\section{Erratum to:}

Chapter 11 in: E.R. Wright and N. Carnes (eds.), Understanding the HIV/AIDS Epidemic in the United States, Social Disparities in Health and Health Care, DOI 10.1007/978-3-319-34004-3_11

The book was inadvertently published with an incorrect city and country name for the author Christine C. George in Chap. 11. It should be the 'Center for Urban Research and Learning, Loyola University, Chicago, IL, USA' instead of Chennai, India. The erratum chapter and the book has been updated with the change.

The updated original online version for this chapter can be found at 10.1007/978-3-319-34004-3_11

\footnotetext{
J. Hilvers $(\square)$

Policy Research Collaborative, Roosevelt University, Chicago, USA

e-mail: jhilvers@ roosevelt.edu

C.C. George

Center for Urban Research and Learning, Loyola University, Chicago, IL, USA

e-mail: cgeorg@luc.edu
}

\author{
A.V. Bendixen \\ AIDS Foundation of Chicago, Chicago, USA \\ e-mail: abendixen@aidschicago.org

